\title{
The Significance of Logistics in Servicing Growing Volumes of E-Commerce
}

Submitted 11/08/19, $1^{\text {st }}$ revision $23 / 09 / 19,2^{\text {nd }}$ revision $25 / 10 / 19$, accepted $20 / 11 / 19$

\author{
Khalyn V.G. ${ }^{1}$
}

\begin{abstract}
:
Purpose: The article highlights the multi-task nature and prospects of the development of the transit potential of warehouse logistics systems, reveals the theoretical and methodological foundations of logistics in the storage and cargo handling system, indicates and confirms the importance of warehousing logistics in the context of servicing the growing volumes of electronic commerce.

Design/Methodology/Approach: For the purposes of developing logistics in the storage and cargo handling system we study the technical and technological support and design developments that have significant potential for increasing the efficiency of logistics processes, and to study consumer behavior in the warehouse services market and transport market trends - warehouse activities.

Findings: Automation significantly simplifies logistics processes, information exchange, remote control and management, optimizes costs by combining various market entities and objects, target groups and parameters of logistics processes on electronic platforms. Integration in modern logistics allows synchronizing the complex information component of electronic services and platforms and activating the formation of a system interface that is common for all elements of the logistics system of warehousing, cargo processing and inventory management.

Practical implications: The results of the study can be implemented in the activities of Russian companies in order to develop the transit potential of warehouse logistics systems.

Originality/value: The significance of this study lies in shifting the emphasis to the need to switch to improved customer service systems taking into account the needs and development of online retail and fulfillment of logistics operators (full-cycle operator: taking goods from the customer's warehouse, responsible storage, packaging, delivery, work with returns), tied to the development of infrastructure, as the foundation for increasing the efficiency, speed and quality of logistics processes.
\end{abstract}

Keywords: Warehousing logistics, e-commerce, development.

JEL Codes: R49, L90.

Paper type: Commentary article: Logistics.

${ }^{1}$ Associate Professor of the Department of Commerce and Logistics, Rostov State University of Economics, vg@sklp.biz 


\section{Introduction}

Logistics in the service sector, as in any other industry of the economic complex, becomes uneven, when moving goods, and is characterized by a discrete stochastic nature. Therefore, it is the field of warehousing and materials handling, where the development of a logistics methodology, a service complex has a composite multivariant nature. The warehousing process in the modern world is based on the development of e-commerce, information business, which bring a certain increase and are implemented by means of increasing in the turnover of consolidation systems.

The traffic flow, which, in a certain category, is incoming for the logistics warehouse complex, has its own qualitative parameters, characteristics, including reserves, time and quality of products. Initially, the cost of land in different states, depending initially on the territory of the country, differs significantly. In this regard, there is a bilateral impact in terms of the development of warehousing and materials handling logistics technologies, since this issue is dual by its nature. On the one hand, the high cost of land does not allow small states to develop certain formats of global warehouse complexes, and the cost of land in the local territories, at borders coinciding with the areas of urbanized lands, centers of trade and economic development and industryspecific profile complexes, is even higher.

Large distribution systems, the population, small organizations, and individuals need to rent additional territories to accommodate a certain kind of things, store and perhaps handle them. There are business projects in city agglomerations that suggest the possibility of not only warehousing in the framework of a separate warehouse building, but also the conditions for placing office centers, auxiliary and other services. This issue is interesting from the point of view of the research theoretical and methodological point of view and by reason of the applied value in the framework of the development of the local territory and the region as a whole, since it fully discloses the features of the innovative development of the warehouse in the framework of e-commerce and the need to build personalized local warehouse capacities.

The development of storage and materials handling logistics complexes with a wide range of work performed to service material and information flows is an innovative solution in the development of the regional economy. The theoretical and methodological foundations of logistics in the storage and materials handling system should be aimed at conducting research and monitoring scientific technical and technological support and design developments, which have significant potential to increase the efficiency of logistics processes.

E-commerce showing an average growth of about $10-15 \%$ per year can significantly adjust regional local and even federal markets in the future. The consumer in the modern world appreciates not only quality and responds favorably to the announcement of the discount, he/she appreciates the time needed to complete the 
purchase process. The role of warehousing in logistics is ambiguous. On the one hand, the general trend is the maximum reduction in stocks. On the other hand, in most cases it is not possible to avoid creating stocks or minimizing them. Therefore, in logistics management, warehousing of products in the logistics system, as a rule, is done in case it allows reducing costs or improving the quality of the logistics service.

In this regard, advanced logistics providers are improving their activities to minimize time gaps regarding the speed and timeliness of response to changing needs. Failures and difficulties in deliveries and in logistics activities in general force the consumer to choose other options, go to competitors, and then choose the best option, which is often the most affordable. The consumer is tolerant of the high quality of both goods and logistics services, because:

- he/she needs only those products that are released and delivered in strict accordance with standards and requirements of federal and world level rather than the regional and local one;

- the goods should be packed and accompanied by the necessary mandatory documentation;

- timely delivery decisively affects the buyer's opinion of the company.

Facilitating internal flow processes is one of the backbone tasks of modern logistics. International logistics systems in the service sector and their accompanying flows can significantly enhance and strengthen the transit potential of the Russian Federation. The ability to provide urgent delivery is the basis for the future development of logistics services in relation to transit. In turn, the development of a logistics methodology in the field of electronic commerce provides significant opportunities not only for network retail, but also for small companies that can operate efficiently only in the local market.

The main drawback of the development of logistics in the Russian Federation is, in our opinion, the lack of investment in infrastructure funds, but at the same time, comparing this issue with examples of other states, it should be noted that there is a lack of interest of private Russian investors. Considering the scale of our state, this problem cannot be solved at a time. Therefore, the most efficient transport and storage facilities for investment should be worked out, considering not only public funding, but also the possibility of attracting business for optimization and concession agreements between parties interested in a common goal and united by it.

A clear global advantage of the current transport and storage situation may be the dynamics of reducing the cost of transportation, as well as an insignificant increase in the cost of warehouse services, materials handling services. On the other hand, a certain negative factor is the lack of integration of transport and warehouse flows in the logistics of the region. In this context, we are talking about general indicators. This situation also affects the safety factors of product distribution. In our opinion, this is 
precisely why multimodal operations and transit are still not getting the proper development in the region.

\section{Theoretical, Empirical, and Methodological Grounds of the Research}

Investigating the logistics of the product distribution systems of the Southern Federal District, the fact that not every company as a logistics provider can ensure the delivery of goods in a short time has been revealed. However, the modern consumer does not want to wait, the competition is quite high, so it is necessary to optimize the temporal indicators and characteristics of the goods turnover, which should be partially adjusted to the minimum. Theoretical and methodological developments in warehousing management are based on global optimization, and it is impossible to get products right away in e-commerce, but the longer the delivery time is, the more significant the discount can be. This idea imposed by the modern market is already firmly kept in the consumers' minds.

Electronic document management is not a novelty for the Russian market, as well as for localized territories united by a single legislative, legal and federal regulatory framework. Indeed, electronic document management in practice has proved its effectiveness, since its introduction on each relatively separate section of the distribution network as part of the configuration of the supply chain and logistics systems is effective in practice and has a certain percentage of financial savings.

Electronic document management does not allow completely excluding the presence of a person, but at the same time, it minimizes his labor costs and greatly simplifies order consolidation. The logistics provider performs an extensive list of functions, while cargo escorting involves the reservation of certain areas, the planning of technical means necessary for the passage of the goods, a set of analytical and control measures that are necessary to comply with the parameters of preservation and integrity of products. This technology carries a complete rejection of a paper document, which in recent years has significantly complicated and not simplified the work of logistics operators.

Automation of business processes should be realized completely and systematically, therefore, uniform standards instilled in the storage and cargo handling system should be distributed everywhere and monitored as well. Automation of electronic platforms makes it possible to connect geographically separated units of the sales network, which can significantly adjust the parameters of logistics costs.

Applying these technologies specifically for multimodal transportation as part of transit operations is of importance. Logistics providers and forwarding companies as the main active players in the distribution systems testify in favor of a general rejection of paper circulation. At the same time, common standards for commercial and shipping documentation can significantly increase the volume of certain markets. At the same time, they can effectively implement and adjust the format of their activities, 
since innovation and readiness for changes in the external environment can significantly reduce the level of risks and costs that are not created in the logistics delivery system, warehousing and cargo handling.

As it has been discussed above, the time period within which the consumer is ready to expect products is significantly narrowing in the field of courier delivery. The most relevant parameters much in demand are delivery "for now", within a few hours from the moment of placing the order.

If the agreed terms are not met, the consumer begins to panic. Most of the innovative technologies for warehousing and materials handling allow using different delivery methods, since innovations are not quite a sensation. They come to lives and are already available after several years of testing. When innovations appeared on the logistics market in the field of delivery - delivery using drones, it was hard to imagine that in a few years a number of foreign logistics companies will use drones in their usual activities, trying to replace a person in labor-intensive processes every day.

\section{Results}

From the point of view of the theory and methodology of warehousing logistics, it should be noted that experts are fixing a constant annual increase in Internet connectivity on a global scale, which is equivalent to 50 million devices per long-term prospect additionally connected to the network until 2020. E-business opportunities and modern logistics are expanding significantly by means of the Internet and cloud services. Automation significantly simplifies logistics processes, information exchange, remote control and management. It can optimize costs by combining various market entities and objects, target groups and parameters of logistics processes on electronic platforms.

Fragmentation between the railway and transport arteries is also observed on the territory of the country and regions, which indicates a decrease in the effectiveness of integration in logistics and transport processes. In our opinion, the varieties of port, road and railway infrastructure should be integrated into a single, efficiently functioning logistics mechanism. That is when logistics operations can be most effective, since this kind of symbiosis gives rise to additional development of the central regions - regional logistics complexes and centers, transshipment hubs capable of servicing large-scale cargo flows on their territory due to technological development.

These multi-figure compositions can be developed, both based on already prepared facilities, and in the creation and construction of new logistics centers. The integration of the interests of the state and business has repeatedly proved its effectiveness in the development of the economic complex of both our state and other countries of the world. That is why the way out is seen in the development of this area, activating 
interest and attracting large-scale investments in the construction and reconstruction of the logistics infrastructure of the country and its regions.

The complementarity of these statements is confirmed by the fact that positive experience of this nature can be ascertained in the dominant part of European developed countries, as well as at the intersection points of trade and transport highways serving large-scale international goods flows. It should be noted that there are negative consequences of this integration (the presence of private road traffic, cost categories and forms of passes for these road objects, and so on).

However, there are much more positive consequences - in this way, the problems of bottlenecks can be eliminated, traffic congestion can be avoided, and large-scale targeted financing can be attracted to the logistics infrastructure. The latter reason is most significant, since over the past few years less than 5\% of GDP has been allocated for the reconstruction of transport links in the Russian Federation. The construction of infrastructure also does not have the proper investment, since our country is experiencing crisis after crisis dynamics of several years, the financing gap also manifests itself as a result, several new active reasons. In this regard, achieving scientific and technological progress, using best available technologies in warehousing and cargo handling, transportation is also important and can initiate the effective development of infrastructure facilities.

Watching the movement of goods in real time is no longer a novelty for logistics operators and transport companies, freight forwarders and other stakeholders. However, the development of e-business, information logistics platforms allows not only to control external parameters, but also to penetrate the very heart of the transportation process, choosing not only the vehicle, but also the driver. At the same time, logistics providers receive guaranteed orders, combining the functions of online cargo tracking and reducing the load on staff on their platform.

Naturally, traditional approaches and technologies in the management of warehouse logistics become outdated very quickly. Therefore, from a theoretical and methodological point of view, automation of warehouse and cargo processes of decades ago significantly differ from modern concepts. Electronic information concepts do not affect the complex designs of modern warehouses, as they should be a priori effective. Therefore, when organizing and operating warehouse management logistics, it is necessary first to develop complex infrastructure issues and the internal technical and technological structure of storage facilities. Integration in modern logistics allows synchronizing the complex information component of electronic services and platforms, and the formation of a system interface that is common for all elements of the logistics system for warehousing, cargo processing and inventory management can be activated, taking into account several parameters. Modern packaging materials also show bifurcate growth in their development, while the characteristics of packaging, palletizing, container transportation in the warehouse management system are most effective and can significantly reduce costs. To choose 
the optimal solution for reserving a site for warehousing, it is necessary to consider the complexity of multifunctional combinations that are different in speed, size and other characteristics.

In the modern context, Russia is considering a legislative project to limit or completely ban services for outsourcing logistics processes. It is needed to figure out what the reason for the complicated tactical and managerial decision is, since the federal level in this regard acts as a regulator, his action based on clear directives and responses, the reaction of regional subsystems.

In this regard, an interesting survey was conducted in the regions and was designed to identify a common opinion about companies that offer business process outsourcing services on the Russian market. There are a significant number of possible combinations in the outsourcing of logistics processes, they vary in completeness, differ depending on territorial coverage and certain conditions. It is assumed that the transformation of market activity that occurred with the advent of the last crisis provides not only threats and problems, but also new opportunities for companies providing logistics services.

Russian outsourcing failed to stand the test of time, as evidenced by analytical reports characterizing the opinions of customers, their reviews of companies that take part of outsourcing processes. It should be noted that most customers are not satisfied with the conditions and quality of outsourcing, which is why the logistics services market is currently undergoing the next significant transformation. Adapting to changing market conditions has proven to be a difficult task for companies in the industry. Therefore, almost all participants in the logistics services market need effective logistics, but when transferring rights to intermediaries, they often lose control

\section{Conclusions and Recommendations}

Companies providing the growth of e-commerce result in showing a steady annual growth by the warehousing and cargo processing segment. It is of note that this is a configuration that can forecast a certain growth in the segment of online retail and fulfillment of logistics operators (a full-cycle operator: taking goods from the customer's warehouse, responsible storage, assembly, packaging, delivery, work with returns). Certain trends in the absorption of warehouse capacity by online trading can be represented as follows:

- firstly, development forecasts are based on the analysis of the activities of federal operators who are trying to more efficiently establish the work of the region;

- secondly, market players and logistics fulfillment operators as the middle link in the logistics system of goods distribution and warehousing of products are becoming active, capable of passing multi-component material flows of all types of goods distribution systems through themselves;

- thirdly, the possibility of building and commissioning their own storage facilities. 
It should be noted that in recent years, the warehouse real estate market has not changed significantly. The general trend remains that the Moscow region and the territory of Saint Petersburg are developing locally. If an increase in the absorption of square meters of storage capacity at the level of three million square meters can be expected in Russia overall, then Moscow market will take half of this indicator. In the Moscow region, the need for high-quality warehouse space is significantly higher than anywhere else in the country.

From a theoretical and methodological point of view, it should be noted that the arrival of new foreign players will be a significant incentive for the development of warehouse real estate, but at the same time developing infrastructure within the domestic market, they will not be able to bring significant results to the country's economic complex, since financial resources will be invested to get their own benefits.

It should also be borne in mind that in addition to a quantitative indicator, qualitative changes in the real estate market, warehousing and cargo handling systems, also provoked by the increase in e-commerce, are necessary. At the same time, considering the integration support of distribution systems, it should be noted that regarding ecommerce at an early stage of development, not only large multifunctional warehouses located at the intersection of basic transport arteries are needed. Integration with e-commerce of the existing infrastructure security of standard offline sales is required. However, every day the growth of competition and the volume of goods turnover require more efficient and effective intervention of logistics. Therefore, online sales are gradually adjusting the market, and the storage capacities that are involved in this process become closer to the buyer, not only territorially, but also qualitatively.

As a result, online trading is transformed into a certain mechanism that can flexibly respond to changing demand. Centralized logistics service system and promising directions for the development of the transit potential of distribution systems are making it possible to provide a more efficient service for online consumers, which provide for the automation of transit functional management processes using an information-process approach.

Now, Russia is increasing the volume of electronic commerce, optimizing the transit potential, which is not fully utilized. At the same time, the next form of e-commerce development is the introduction of fulfillment complexes and online platforms within the framework of a traditional existing business. Because the warehouse infrastructure of electronic commerce is focused on timely after-sales service of many customers, warehouses and distribution centers play the largest role in this activity. The evolution of online trading leads logistics to the need to move to improved customer service systems. The leading role in this process undoubtedly belongs to the development of infrastructure as the backbone for increasing the efficiency, speed and quality of logistics processes. 
The growth of e-commerce volumes on the example of many developed countries forms a certain type and structure of logistics distribution systems, which includes not only a distribution complex (warehouse), but also a fulfillment center. Urban logistics in its development should reach the points of delivery of orders in the format of post mats. In our opinion, the Russian market has all the prospects for further effective development, providing all the conditions for the timely quality delivery of goods to the client's home.

But at the same time, e-commerce is extremely difficult in terms of organizational and functional management. Multidisciplinary product groups, millions of products, companies that offer a wide product matrix cannot always focus on the optimal efficient consolidation process. In this perspective, it is not necessary to switch from simple solutions to more complex ones and to the need of increasing the territory of warehouse and cargo handling complexes. It is just necessary to optimize the logistics processes, giving them the property of increasing turnover.

In this regard, the market knows enough examples, as a result of which errors and insufficient logistics efficiency can be eliminated. Some experts recommend limiting the number of product groups on one pallet, while others talk about the need to abandon multi-tier storage, but in fact optimization may not be achieved even with these measures. The way out is seen in the fact that logistics is becoming individualized due to the growth of Internet sales, and the construct of traditional retail is gradually changing.

However, in fairness, it should be noted that most of the facilities still designed for the construction of storage have already been purchased and leased. It cannot be stated that the Russian market is fully provided with the necessary infrastructure and storage facilities. Earlier, we presented several salient trends that provoke and ensure the growth of commodity circulation, which undoubtedly testifies in favor of increasing warehouse capacities.

From a theoretical and methodological point of view, it should be noted that the arrival of new foreign transit players will be a significant incentive for the development of warehouse real estate. But it may happen that developing infrastructure within the domestic market, they will not be ready and will not be able to bring significant payments to the country's economic complex, since financial resources will be invested to develop and obtain their own benefits.

It should also be borne in mind that in addition to the quantitative indicator, qualitative changes in the real estate market, warehousing and cargo handling systems also provoked by the increase in electronic commerce and other factors are also required. At the same time, considering the integration support of distribution systems, it should be noted that e-commerce at an early stage of development needs not only large multifunctional warehouses located at the intersection of basic transport arteries. Integration of e-commerce and the existing infrastructure of offline sales is needed to 
a greater extent. However, with each passing day, increased competition and sales volumes require more efficient and effective logistics intervention.

The world's most famous analytical and research agencies predict the growth of the Russian warehouse segment for the next 3-5 years, which will increase the absorption volume of goods turnover by Russian companies by about one and a half to two million square meters. Undoubtedly, a part of the goods turnover in the south of Russia is growing due to transit operations.

\section{References:}

Bowersox, D.J. 2017. Logistics. Integrated Supply Chain. Moscow, Olymp-Business, 939.

Khalyn, V.G. 2011. Restructuring of the information system of regional distribution complexes based on the use of innovative logistics tools. Terra Economicus, 1, 2-11.

Levikov, G.A. 2017. Logistics, transport and forwarding. Brief dictionary-reference book. Moscow, TransLit, 224.

Plokhikh, Yu.V., Gubich, M.E. 2015 Prospects and problems of transport and logistics services market development. Young scientist, 9(89), 685-686.

Volgin, V.V. 2016. Storekeeper. Arrangement of warehouses. Warehouse operations. Warehouse Management. Moscow, Axis-89, 544. 